\title{
Metacognition, Mindfulness and Robots for Autism Inclusion
}

\author{
https://doi.org/10.3991/ijes.v8i2.14213
}

\author{
Eleni Mitsea, Niki Lytra, Antigoni Akrivopoulou, Athanasios Drigas ${ }^{(\bowtie)}$ \\ Net Media Lab-Mind \& Brain R\&D, \\ N.C.S.R. 'Demokritos', Athens, Greece \\ dreit.demokritos.gr
}

\begin{abstract}
Autism is a neurodevelopmental disorder with multifactorial causes, characterized by major cognitive deficits in communication, socialization and emotion recognition and management. Children with autism face a memory mechanism malfunction, difficulty in the control processes (i.e attentional regulation and / or organizing their knowledge in order to make the appropriate decisions solving problems), making it difficult for them, adapt to various environmental changes. Many researchers have shown the effectiveness of robots in developing metacognitive skills to autistic children, as well as in improving social skills, emotion awareness and communication. This article highlights the detailed research took place between 2010 - present, while examining the impact of robots on autistic children through their interaction, use of art, programming, cooperative games and mindfulness training. The outcome of this review emphasizes to the ability of children, to manage and develop mechanisms such as self-control, self-reflection, visualization, focus attention, selfevaluation, self-regulation among others, necessary for their self-awareness. These results to helping children develop the higher mental abilities needed, so that decision-making and problem-solving achieved in their daily life.
\end{abstract}

Keywords - Autism, human-robot interaction, robots design, cognitive deficits, executive functions, metacognition, mindfulness, coding

\section{Introduction}

Autism is a neurobiological [1] and multifactorial disorder [2], which is characterized by some cognitive deficits. In this paper we have analyzed specifically dysfunction not only in language and attention, such as joint attention but in control and memory, such as working memory as well, based on scientific studies [3, 4, 5].

In addition to the cognitive deficits of autism, this article also deals with the characteristics, the functionality and the use of robots as intervention and treatment tools for autistic individuals. It has therefore been shown that the use of robots in the learning process reduces the cognitive and sensory deficits of people with this disorder while enhancing the development of metacognitive skills [6]. This is also due to the fact these children prefer contact with robots than people, because robots are simpler, 
predictable and repeatable [7]. Speaking of the interaction between these individuals and the robots, we must mention the advantages gained in this process which are the enhancement of imitation, joint attention, initiation of communication and social interaction [8].

Art and game are considered as effective ways to promote self- regulation skills involved in learning [9]. Mindfulness-based activities foster executive functions by activating control mechanisms, such as attentional control [10]. Programming robots foster higher cognitive, social and emotional abilities [11]. Thus, in the last section, we opt to present researches that leverage robots in the aforementioned frameworks in order to investigate whether people with autism could be benefited improving cognitive and metacognitive skills. The results showed that there were remarkable improvements.

\section{Autism}

Autism spectrum disorder is a complex neurobiological disorder characterized by abnormal social interaction, lack of communicative skills and stereotyped behavior. It is derived from the Greek word "autos", meaning an isolated self, in which a person keeps himself detached from surrounding interactions [1]. This neurodevelopment disorder appears before the age of 3 [2]. According to researches, it has been found many different causes, which are connected with autism [12]. Some of these factors are genetic and some others are environmental. [2]

\subsection{Cognitive deficits of autism}

Quality deficiencies in language and communication: The degree of communication impairment can vary in people with autistic disorder [13]. Linguistic disorders that may exist are due to abnormalities in the brain structures, which in turn affect memory systems and consequently linguistic and non-linguistic abilities [14]. If there is speech, it often appears delayed. In some cases, it is unnatural and it looks like robotic, with a tendency to be raised the tone of voice at the end of a sentence as if it were a question. There is often a great deal of difficulty in starting or maintaining a conversation [13]. We would therefore say that people with autism have deficits in pragmatics, which is the knowledge of social rules that are necessary within a communication framework, including verbal and non-verbal aspects of communication [14].

Children with autism can be very imitative in the vocal field and often repeat what they have been told (echolalia) instead of giving an answer [13]. But when these individuals give answers, they may be inadequate on issues that may not be familiar to them and generally they may not provide all the necessary information to the interlocutor in order to achieve an effective communication. Difficulty in narration has also been observed [14]. Moreover, they are often confined to monologues, instead of being interested in reciprocal verbal transactions. 
It is worth noting that these children have difficulty with the comprehension of the metaphorical meaning of speech (e.g. put oneself in someone else's shoes) [13]. So they interpret the words literally. Other non-literal statements that are difficult to be understood by people with autism are jokes, sarcasm, lies, bluff and irony [14].

An early specimen of a deficit of nonverbal communication in young children with autism is the delay in first gestures. Gestures, for example, to share their interest for an object or to direct attention to an event [14]. Finally, autistic individuals are sensible in the way you address them. They cannot stand loud voices and avoid the discussant who looks them in the eyes [15].

Cognitive control deficits: Control mechanisms enable the individual to guide his thoughts and therefore his actions, keeping the information active, which are necessary to achieve the behavioral goal. In other words, cognitive control results in a flexible behavior that can respond to a changing environment. Experimental studies have showed that typical people can alternate from one project to another quickly and easily. On the other hand, people with cognitive deficits such as those with autism display errors during switching projects. The autistic individuals have difficulty to understand others' expectations and in this case the expectations of the experimenter [16].

Executive control consists of a set of cognitive processes such as cognitive flexibility, working memory, inhibition, planning, and action monitoring that contribute to coordinating behavior to achieve a future goal. They also help to regulate emotions as well as to maintain attention. Research shows that people with autism have deficits in many of the aforementioned cognitive processes and executive control in general [17].

In respect to stimulus control people control their behavior based on their sensory information. On the contrary, the behavior of autistic individuals is characterized by repetition and rigidity [16]. Parents of children with autism have described them as either overactive (easily disturbed by external stimuluses) or as hypoactive (they do not react to external stimuluses). When these children's senses are overwhelmed by stimuluses, they are relieved by hyper-focusing on a repetitive dysfunctional activity (putting their toys in order) or by the rigid adhesion to the usual. Deficits in the organization and filtering of information can cause sensory overload [13]. In addition, according to Lovaas (1979) [18], autistic individuals exhibit stimulus overselectivity, implying weakness rather than voluntary stimuli selection to response. In other words they are unable to respond to multiple cues.

Speaking about cognitive behavioral control, we could also make a brief reference to empathy at this point of the article. The word "empathy" implies the ability to understand another's emotional and mental stage and react with an appropriate action or emotion. Empathy has two dimensions, the cognitive empathy and the emotional empathy. The first one implies the individual's ability to be aware of another's perspective. The second one refers to the observer's appropriate emotional response to the mental state of others. Autistic individuals have difficulty to respond to all these [19]. In particular, children with autism cannot assess the feelings of others and understand other people's facial expressions and body language in general. They are indifferent to the positive or negative consequences of their actions, which can affect other people, including their family members. A child with autism may laugh while another is crying [15]. 
Memory deficits: Memory enables the individual to utilize past experiences to shape and manifest a future behavior. This ability requires memorization and coding of experience in order to be allowed its retrieval either intentionally or unintentionally [20]. While people with autism are considered to have great rote memory abilities, deficits in other aspects of memory create a dysfunctional condition.

Starting with working memory, we would say that is the process by which information is kept active for short periods of time. In experimental studies, the level of working memory of autistic individuals has been tested either by performing specific and relatively simple tasks or by performing more complex problem-solving tasks. According to the results, as the complexity of the activities increased, participants' performance decreased and made more mistakes. Deficits in working memory create problems in cognitive flexibility, in regulating behavior and in maintaining attention to abstract thinking [21].

Continuing with episodic memory, it has been reported that autistic individuals display difficulty to memorize events as well as impairments to use organizational strategies to support recall. With regard to selective memory and specifying timing of events, it has been found that people with autism have deficits. This can be explained by the difficulty in remembering stimuli related to time of occurrence, which is linked to short-term memory. Short-term memory deficits also result from the difficulty of processing the relationships between the elements of experience, while these elements are retained in memory. At this point it is worth noting that despite various memory deficits there are reports arguing that verbal memory span is intact in children with autism [22].

Attention deficits: Attention deficits are one of the main features of autism [23]. Joint attention is one's ability to coordinate his attention with another's attention within a social context in order to share a perceptional experience. It also helps the individual in processing information in order to perceive his intentions and others' intentions. The development of joint attention begins at the $3^{\text {rd }}$ to $9^{\text {th }}$ month of life [24]. Studies have showed that young autistic people perform poorly on activities of joint attention compared to typical young people.

Visual attention is an integrant part of social interaction as well as an important element for the development of other areas (e.g. language development). According to research findings 14-month-old high risk infants who were diagnosed later with autism at age of 3 , showed poor visual attention compared to infants with typical development.

It has been shown that interventions can improve the flexibility of attention and the visual signal evaluation, something that could lead to the improvement of social attention generally [23]. In respect to joint attention, the improvement of this form of memory can make changes which in turn reduce the potency of autism deficits. In other words, early interventions on joint attention have a positive impact on social learning [24]. 


\section{Robot Design Features}

Robots tend to be designed, with the age and real needs of children, [25], thus activities should be scalable and targeted in real time, at each child's cognitive level [8, 26, 27]. According to Giullian N. et al. [26] and Cabibihan et al. [8], the design specifications and requirements of a robot, are necessary to evaluate their effectiveness. Both agree that design and function consist important factors and refer to design, functionality, safety and autonomy. Cabibihan et al. [8] underlines, two additional requirements, structural and adaptability.

Interaction of autistic children with robots, is attractive and affordable, as a result of the reduced complexity of understanding people using facial expressions [27, 28]. For this reason, complex facial expressions should be avoided, when being designed.

According to Robot's physical appearance divided into three major categories humanoid, non-humanoid and non-biological robots. Humanoid robots are those very similar to humans, non-humanoid are those that simulate animals or cartoons and nonbiological are those that do not have vital characteristics such as a robot car.

Many researchers refer that children through interaction with humanoid robots, generalizing their acquired behaviors to real people easier, but tend to be more attracted to non-humanoid robots expressing more emotions about pet robots for instance, even if physical contact is needed [28, 29]. Therefore, in case where learning of emotions and interaction with other people required, the use of humanoid robots is essential. However, according to Tschope N. et al. [30], Mc Dorman et al.[31] and Tung F. [32] the degree of anthropomorphism and emotion expression of robots should be studied carefully when designed, to avoid the risk of being overly realistic, resulting to creating fear to the children and the robot purpose being less effective.

\subsection{Different roles of robots}

Robots can have different roles depending on the content, the trainer, trainee and nature of the activity. They can be either passive (robots in the role of tools) or active (robot as trainers or peers or companion), [7]. The robots according to their role categorized, as shown below [8]:

Diagnostic agent: Early diagnosis allows early intervention in students with autism, increasing the chances of improving the behavior of these children. Nevertheless, Campolo D. et al. [33] claims that early diagnosis of autistic children, is extremely difficult before the age of 3 , because they have not developed enough cognitive functions, such as speech, which are needed for examination. Boucenna et. al. [34] states that robots can elicit behaviors that may be useful for early diagnosis.

Playmate friendly agent: Robots can engage in a fun and interactive activity with children by helping them develop cognitive and social skills, in order to generalize these skills with their peers.

Agent that elicits behaviors: Robots in therapy act to elicit desirable behaviors, such as imitation, eye contact, initiation of interaction by the child, turn talking activities, joint attention and emotion recognition, behaviors that will be vital for children's communication. 
Social Mediator: The robot has a mediating role between a child and a therapist. To educate child on social skills that extends learning behaviors for social interaction with peers. This includes group therapy, where two or more children interact with the same robot at the same time.

Social actor: Robots display acceptable behaviors per social circumstance, giving children learning opportunities through observation.

Personal assistant: Robots provide personalized treatments for each child, depending on the child's preferences, needs and difficulties

Beldame T. et al. [35] distinguishes robots, based on their roles to 'tutor robot', 'robot as a peer', 'robot as notice'. As a tutor robot, provides direct support to a curriculum. These robots focus on personalized teaching, one-to-one interaction. In this case, robots do not target so much on interacting with students but aim at improving attention and learning motivation. Robot as a peer is less intimidating than robots as a tutor. Interactions between peers can have a positive impact. This is often presented as a peer with more knowledge than the student, guiding him or her in a learning activity that is neither too easy nor too difficult for the student. The robot as a beginner described as a peer with less knowledge than the child and allows the student to play the role of expert, thereby improving his / her confidence while establishing learning outcomes. The student tries to teach the robot with immediate results at his or her own cognitive level. This type provides the opportunity to develop metacognitive skills, as students commit to teaching the robot educational material that requires a high level of understanding.

\subsection{Behaviors stimulate by robots}

The interaction of autistic children with robots, aims to improve their social skills, emotional awareness and communication through the elicit of desirable behaviors such as imitation, joint attention, initiation of communication and social interaction.

Imitation: Imitation is a very important factor in the transfer of knowledge. It develops children physical and verbal skills that help them explore their environment and identify behaviors of their peers, improving their communication [8]. Robins B. al. [27] argues that through imitation, 'turn - talking' activity is also achieved, as the child must learn to wait for a response before reacting. The interaction through imitation is described by Boucenna S. et al. [34], as a complex process that takes place through three phases: (a) Observation, which is, the necessary given attention, when monitoring an action performed by a human. (b) Understanding, which involves creating and memorizing an internal representation of the observed work or behavior, and (c) The reproduction of the observed work or behavior.

Joint attention: Children with autism often lack the ability to consciously focus on the same subject and/or person. Joint attention is a key factor for their success in learning. Boucenna S. et al. [34] considers it, as a very important factor for social interaction along side with imitation and attention. Cabibihan et al [8] agrees with this proposal, stating that the robot enhances the joint attention, initially leading the child to look at the same target or object through hand movements and gaze. Ricks et al. 
[28] argue that children with autism through interaction with robots can focus to them, as peers with typical development can do.

Initiation of communication: Koegel R. et al. [36] report that children with typical development are able to initiate a discussion (asking questions) during their interaction. On the other hand, children with communication impairments are unable to initiate and guide a conversation. Their strategy includes the development of language learning and social skills. According to Ricks D.J et al [28] robots are programmed to teach such skills by encouraging children through their interaction to gradually acquire the ability to create and maintain a conversation.

Social interaction: Unlike to the highly complex and unpredictable behavior, result of peoples' social interactions, use of robots allows, a simplified, safe, anticipated and reliable environment, through which the complication of interaction can be controlled and gradually increased. Children with autism, have difficulties becoming familiar with social skills. Robots help children getting to know the appropriate behavior, through the interaction with them, as a result of an indirect experience. These robots implementing suitable behaviors through specific social situations, in an aim to offer child, the opportunity to learn, through its predictable but progressively changing actions [8].

Through the above behavior's children can improve the contact eyes, one of the most fundamental mechanisms of social cognition. "Eye contact is the joint action of two individuals looking into each other's' faces, especially through their eyes.", (Kozima H. [37]). Gaze direction, facial expressions and temporally synchronized interactions, included as well. Children can also improve the emotion recognition and expression. Robots repeated more than people, which prove to teach these kids becoming familiar with facial expressions and emotions [28].

\section{$4 \quad$ Meta-Cognitive Training Through Robot-Based Intervention}

\subsection{Intervention with robots in art and game therapy}

Music is tightly associated with metacognition and autism therapy. Music requires bottom-up and top-down perceptual processing, attention, and integration of executive functions [38]. Chella et al. [39] built a robotic setup in which the Telenoid, a portable teleoperated android robot, could learn to improvise jazz singing in a duet with a human singer. The described system could be used as a music game in which the children with autism could be engaged in singing in rhythm at the right tempo with the Telenoid. Taheri et al. [40] used Darwin-Op, a humanoid robot to interact with two children aged 8 years old with severe autism in a music therapy game. The robot had to imitate the notes which the child had played on a xylophone, and then the child had to imitate the robot in return. The results showed that attention and concentration were improved, as well as social skills including interpersonal synchrony.

Robotic dance intervention has attracted interest in the case of autism therapy. Dance includes a wide range of social behaviors [41] and constitutes a natural means of emotional expression [42]. It develops self-control, especially in reactions to feel- 
ings such as anger and fear [43]. Moreover, it provides a means to communicate and share feelings. Conti et al. [44] tried to stimulate imitation in 3 children with ASD and ID and limited attention span. The main activity consisted of an imitation game in which the child was engaged first as imitator and then as initiator of robot choreography. In this process, the robot tried to engage the child's memory as well as to improve eye-gaze and interaction. The results showed that the imitation skills were improved resulting in social awareness and positive social behavior. Moreover, bodyawareness and, by extent, self-awareness and the ability to initiate interaction were promoted.

So et al. [45] has adopted a play drama intervention protocol with the application of robots with the aim to develop narrative skills. For 12 weeks, twenty six children diagnosed with autism, aged four to six years old watched three dramas in which two Nao robots were used as actors. Afterward, the children were given the opportunity to be engaged in role plays with both robots and human experimenters. Results showed improvements in narrative measures such as narrative length and syntactic complexity. Syntax and executive functions are related, since comprehension and production of grammatical structures and combinations require the engagement of cognitive processes such as attention, memory, flexibility, and inhibition [46]. Moreover, the children could describe the causal and temporal structure and identify characters goals and their attempts to achieve them. Their ability to represent events improved so they were able to understand how the scenes were linked as a result of human response to situations. Their gestural communication was improved. They seemed to understand the meaning of these gestures in each context. The aforementioned results indicate also signs of improvement in working memory [47], joint attention skills, perspective taking skills (empathy), and motivation.

Cooney et al. [48] focused on robots capable of painting with a person and reading their emotions through a brain machine interface. Various robots such as Turtlebot, Thymio, ARDrone, Nao and Baxter could be utilized in different frameworks. The robot's involvement in painting depends on the user's wish. More specifically, patients can either passively observe, or be independent. The robot provides scaffolding, keeps track of time and progression, tries to stimulate self-reflection, adjusts the challenge, and recognizes user's emotions through conversation. In some cases, it can suggest topics such as self-portraiture as a way to promote self-reflectance and selfacceptance [49]. Moreover, it can help humans paint better resulting in selfaccomplishment, motivation and ownership [50]. Robot-based painting therapy could improve self-awareness, self-image and relaxation via processes of self-exploration, self-fulfillment, and catharsis [51]. In addition, it could facilitate hedonic and eudaimonistic aspects translated in increased levels of dopamine, serotonin, reduced amygdala activity and calmed limbic system. As a conclusion, patients with autism could, on the one hand, regulate strong emotions including negative ones, to reduce stress, and on the other hand, improve skills such as time management, goal-setting, decision making, and problem solving.

Zhang et al. [52] used the social robot Nao, so as to find out how children with autism learn complex social rules through distrust and deception games. Previous research has shown that children's tendency to trust and their understanding of decep- 
tion is significantly related to Theory of Mind and inhibition control [53] as they have to manipulate their false beliefs. In this study, twenty children between the ages of 5-8 participated in the game to find the hidden tokens. In the distrust task, the robot tried to misinform the children about the location of the token, while in the deception task children were asked to hide the token and deceive the robot. Results showed that although children with ASD experienced difficulty, they could still learn to adjust their distrust and deception behaviors improving their social learning.

Chess training robots could be beneficial for highly intelligent autistic children. Chess playing stimulates knowledge acquisition processes such as representation, attention, recall memory, concentration, problem solving, planning strategies and creativity [54]. There are many robotic systems that could be used such as the humanoid robot Baxter and Marti module, an autonomous chess module [55], Gambit, an autonomous system with a 6-Dof robot arm [56] and a Chinese chess robot [57]. In case of autism patients, chess robots could additionally help patients to acquire turntaking skills, to be patient with less anxiety, to be more motivated, and feel confident.

In contrast to the traditional digital serious games where the human is playing with a computer, human-robot interaction excels because it includes a physical entity, eliciting diverse behaviors and strong emotional responses. Thus, this might support higher motivation, decision-making performance and focus [58]. Jercic et al. [59] used a non-humanoid robot to collaborate with a human player in a turn-taking version of the serious game The Tower of Hanoi. It was concluded that non-humanoid robot partners could induce a better decision-making performance and more positive valence.

\subsection{Intervention with robot trainers in mindfulness therapy}

Tsiakas et al. [60] presented a robot yoga trainer that monitors a training session, adjusts the session parameters according to human motion activity recognition, evaluates through depth data and assists user following a Reinforcement Learning approach. Specifically, a Nao robot demonstrates prescribed exercises and the user performs the demonstrated exercises along with the robot. The system monitors the exercise execution and modifies the session to help the user to perform efficiently. An interactive avatar could be integrated in the aforementioned framework. Yoga fosters cognitive-motor skills, joint proprioception, attention and alertness [61, 62, 63]. Moreover, it is easy to learn and modifiable, based on the age and level of functioning of the child [64]. Finally, yoga promotes mindfulness, a metacognitive ability related to self-consciousness, self-awareness, self-regulation, working memory, cognitive flexibility, self-efficacy as well as cognitive reasoning and problem solving [10].

Goertzel et al. [65] presented Sophia, a robot capable of interacting with people in compassionate ways to promote mainly people's self-understanding, selfaccomplishment and self-transcendence. In a small pilot study involving 10 human participants, Sophia led them through dialogues and meditation exercises, to feel relaxed and develop the cognitive function of visualization. The results showed that human-robot interaction could promote self-development, well-being and advance consciousness. Meditation practices modify motivations, and by extend, self and emo- 
tional regulation processes such as attentional control and conceptual processing [66]. In the case of autism, patients could, on the one hand, reduce stress, depressive symptoms and on the other hand, improve physical health, self-esteem and positive mood.

Wama et al. [67] and Chen et al. [68] suggested a humanoid robot called Metal Fighter that performs 24 fundamental Tai Chi actions based on communication with human. Tai Chi combines intense mental focus with smooth movements improving strength, agility and balance. Sarabzadeh et al [69] examined the effects of tai chi training on 18 children with autism aged 6-12 years. It was found that children improved balance and motion coordination, as a result of simultaneous improvements in self-control, focus attention and memory functions. Tai chi training combined with robot intervention seems to be a promising therapeutic program that could enhance self-regulation through self-synchronization. Wang et al. [70] suggested robots capable of fostering human-robot interaction using Tai Chi control techniques such as mutual learning, intention detection, adaptation behaviors and force borrowing techniques. The wearable robots could be used to help patients to move synchronously with the robots, adopting mutual behaviors and control strategies. In this process, any decision making of each one should consider the other one's changing dynamics as part of its feedback.

Costescu et al. [71] examined whether a social robot, My Keepon could teach children with ASD adaptive behaviors and strategies, so as to regulate the intensity of their negative emotions and modify their dysfunctional beliefs. Twenty-seven children aged 6-12 years, were randomly assigned to either robot-enhanced therapy (12 children) or treatment as usual group (15 children). In the first two sessions of the RET group, the children after being presented fifteen different situations which may trigger anger or sadness, were taught to distinguish emotions and to use appropriate social answers and strategies. Afterward, discussions about the connection between cognitions, emotions and behaviors followed. In the last sessions, children were presented some adaptive strategies that can be practiced in different social situations that are associated with negative emotions. They were also introduced to some techniques for anger management and self-control (e.g. breathing exercises). The findings showed that robot-enhanced therapy could improve self-regulation skills and by extension cognitive and social flexibility.

\subsection{Programmable robots for higher mental abilities}

Robotics can be an effective way for students with autism to develop 21st century skills including various higher mental abilities such as problem solving, abstract and creative thinking, reasoning, pattern recognition, known also as computational thinking. Programming requires the students' ability to break down problems, find similarities or differences, create general principles and design step-by-step instructions. Higher mental abilities derive from the programmers' self-awareness through realistic self-assessment. Thus, the learners should be able to observe themselves and control automatic responses in favour of goal appropriate action, retaining and manipulating visuo-spatial and verbal information in working memory, shifting or switching between two or more tasks [11]. Programming, because of its complexity, is often per- 
formed as a team-based task [72] so it requires also higher social and emotional skills such as collaboration, empathy, discrimination of emotions, conflict management, responsibility, resilience and self-esteem.

Teaching of coding is specifically lacking in the research of students with ASD. However, many affordable programmable robots could be used for teaching coding to autistic students. Knight et al. [73] evaluated the effects of teaching coding via explicit instruction to a ten years old boy diagnosed with ASD and severe behavioral problems. For this study, they used Ozobot, a commercially hand-held smart robot capable of using sensors to follow lines and read color codes the child makes with markers. Thus, the child drew tracks and bits of code on paper, so as to manipulate the robot's actions. The results showed that the student was able not only to code the robot so as to move fast but also generalize his coding skills to a novel exemplar. Albo et al. [74] examined whether the KIBO robot could foster the acquisition of basic programming principles in students with severe ASD. For a total of eight sessions per participant, twelve children with ASD between 6-14 years were shown how to program the KIBO a robot capable of dancing, cleaning itself and travelling from one point to another. The results showed that some participants learnt programming concepts, demonstrated coding abilities including more advanced capacities such as debugging, and improved their social behavior. Future research could attempt to use Edison, a programmable robot designed for teaching young children of all ages and abilities the basics of computational thinking and computer programming creatively. It can be programmed using pre-set barcodes and via a range of programming languages with increasing difficulty [75]. Lego Mindstorm robot constitutes a building kit that allows users to create and program their own robot. Lego boost is the newest robotics set aimed at young children aged 7 years old. Children use easy icon-based coding, so as to create and code multifunctional models [76]

\section{Conclusion}

The current study has shown that autistics' metacognitive mechanism dysfunctions lead to cognitive and emotional deficits. Especially the control processes such as stimulus and behavioral control act up leading to behaviors characterized by repetition, rigidity and apathy. Control deficits are interdependent with malfunctions of memory and attention functions. The purpose of the current study was to investigate the effectiveness of robots as tools to improve cognitive and metacognitive dysfunctions leading to new brain structures, higher levels of intelligence and higher states of consciousness. The use of robots allows an adaptable, simplified and reliable environment that fosters interaction. Children with autism prefer robots because of their appearance and the small range of emotions they are programmed to behave. Moreover, robots are designed taking into consideration the age and real needs of children in real time. They are capable of eliciting desirable behaviors such as imitation, joint attention, initiation of communication and social behaviors.

In search of intervention frameworks that foster metacognition in autistic patients, it was shown that robot-based art therapy enhanced patients' motivation, empathy and 
self-control in reaction to feelings such as anger and fear. Moreover, attention, memory and concentration were improved. Patients developed social skills and adopted more positive behaviors. They were able to adequately handle inhibitions and false beliefs when engaged in problem-solving activities. Robots as mindfulness trainers were able to strengthen patients' self-observation and control processes such as attentional control leading to less negative emotions and depressive symptoms, more positive mood and higher self-esteem. Lastly, programmable robots led patients to the development of higher cognitive abilities such as problem solving, decision-making, reasoning, abstract thinking, and pattern recognition. At the same time, patients through coding were engaged in teamwork tasks that foster higher social and emotional skills such as conflict management and resilience.

\section{References}

[1] Bhat, S., Acharya, U., R., Adeli, H., Bairy, G., M., Adeli, A., (2014), Autism: cause factors, early diagnosis and therapies, Review in Neuroscience, 25(6): 841-850. https://doi. org/10.1515/revneuro-2014-0056

[2] Ratajcak, V., H., (2011), Theoretical aspects of autism: Causes- A review, Journal of Immunotoxicology, 8(1): 68-79

[3] Magalhães, C. G. D., Barbosa, P. G., Abreu, C. S. D., \& Cardoso-Martins, C. (2012). Early joint attention deficits in autism: evidence from a retrospective case study. Brazilian Journal of Psychiatry, 34(4), 509-510. https://doi.org/10.1016/j.rbp.2012.04.004

[4] Millichap, J. (2004). Broca's Area Asymmetry and Language Deficits in Autism. Pediatric Neurology Briefs, 18(12). https://doi.org/10.15844/pedneurbriefs-18-12-2

[5] Cornoldi, C., Marzocchi, G. M., Belotti, M., Caroli, M. G., Meo, T., \& Braga, C. (2001). Working memory interference control deficit in children referred by teachers for ADHD symptoms. Child Neuropsychology, 7(4), 230-240. https://doi.org/10.1076/chin.7.4.230.87 $\underline{35}$

[6] La Paglia, F., La Cascia, C., Francomano, M. M., \& La Barbera, D. (2017). Educational robotics to improve mathematical and metacognitive skills. Annual Review of Cyber Therapy and Telemedicine, Volume 15

[7] Huijnen, C. A. G. J., Lexis, M. A. S., \& de Witte, L. P. (2017). Robots as new tools in therapy and education for children with autism. International Journal of Neurorehabilitation, 4(4), 1-4.

[8] Cabibihan, J. J., Javed, H., Ang, M., \& Aljunied, S. M. (2013). Why robots? A survey on the roles and benefits of social robots in the therapy of children with autism. International journal of social robotics, 5(4), 593-618. https://doi.org/10.1007/s12369-013-0202-2

[9] Whitebread, D. (2010). Play, metacognition and self-regulation. Play and learning in the early years, 161-176.

[10] Drigas, A., \& Karyotaki, M. (2018). Mindfulness Training \& Assessment and Intelligence. International Journal of Recent Contributions from Engineering, Science \& IT (iJES), 6(3), 70-85. https://doi.org/10.3991/ijes.v6i3.9248

[11] Di Lieto, M. C., Pecini, C., Castro, E., Inguaggiato, E., Cecchi, F., Dario, P., \& Cioni, G. (2019). Robot Programming to Empower Higher Cognitive Functions in Early Childhood. In Smart Learning with Educational Robotics (pp. 229-250). Springer, Cham. https://doi.org/10.1007/978-3-030-19913-5_9 
[12] Benvenuto, A., Moavero, R., Alessandrelli, R., Manzi, B., Curatolo, P., (2009), Syndromic autism: causes and pathogenetic pathways, World J Pediatr ,5(3):169-176. https://doi.org/ 10.1007/s12519-009-0033-2

[13] Wilmshurst, L., (2011), Abnormal Child Psychology: A Developmental Perspective, Gutenberg

[14] Walenski, M., Tager-Flusberg, H., \& Ullman, M. T. (2006). Language in autism.

[15] Polichronopoulou, S., (2012), Children and adolescents with special needs and disabilities, Athens: private publication

[16] Poljac, E., \& Bekkering, H. (2012). A review of intentional and cognitive control in autism. Frontiers in psychology, 3, 436. https://doi.org/10.3389/fpsyg.2012.00436

[17] Smithson, P. E., Kenworthy, L., Wills, M. C., Jarrett, M., Atmore, K., \& Yerys, B. E. (2013). Real world executive control impairments in preschoolers with autism spectrum disorders. Journal of autism and developmental disorders, 43(8), 1967-1975. https://doi. org/10.1007/s10803-012-1747-x

[18] Lovaas, O. I., Koegel, R. L., \& Schreibman, L. (1979). Stimulus overselectivity in autism: a review of research. Psychological bulletin, 86(6), 1236. https://doi.org/10.1037/0033-290 9.86.6.1236

[19] Harmasen, I., E., Empathy in Autism Spectrum Disorder, (2019), Journal of Autism and Developmental Disorders, 49:3939-3955. https://doi.org/10.1007/s10803-019-04087-w

[20] Bowler, D. M., Gaigg, S. B., \& Lind, S. E. (2011). Memory in autism: Binding, self and brain.

[21] Williams, D. L., Goldstein, G., Carpenter, P. A., \& Minshew, N. J. (2005). Verbal and spatial working memory in autism. Journal of autism and developmental disorders, 35(6), 747. https://doi.org/10.1007/s10803-005-0021-X

[22] Poirier, M., Martin, J. S., Gaigg, S. B., \& Bowler, D. M. (2011). Short-term memory in autism spectrum disorder. Journal of abnormal psychology, 120(1), 247. https://doi.org/10.10 $\underline{37 / \mathrm{a} 0022298}$

[23] Jaworski, J. L. B., \& Eigsti, I. M. (2017). Low-level visual attention and its relation to joint attention in autism spectrum disorder. Child Neuropsychology, 23(3), 316-331. https://doi. org/10.1080/09297049.2015.1104293

[24] Mundy, P., Gwaltney, M., \& Henderson, H. (2010). Self-referenced processing, neurodevelopment and joint attention in autism. Autism, 14(5), 408-429. https://doi.org/10.1177/1 $\underline{362361310366315}$

[25] Mubin, O., Stevens, C. J., Shahid, S., Al Mahmud, A., \& Dong, J. J. (2013). A review of the applicability of robots in education. Journal of Technology in Education and Learning, 1(209-0015), 13. https://doi.org/10.2316/journal.209.2013.1.209-0015

[26] Giullian, N., Ricks, D., Atherton, A., Colton, M., Goodrich, M., \& Brinton, B. (2010, October). Detailed requirements for robots in autism therapy. In 2010 IEEE International Conference on Systems, Man and Cybernetics (pp. 2595-2602). IEEE. https://doi.org/10. 1109/icsmc.2010.5641908

[27] Robins, B., Otero, N., Ferrari, E., \& Dautenhahn, K. (2007, August). Eliciting requirements for a robotic toy for children with autism-results from user panels. In RO-MAN 2007-The 16th IEEE International Symposium on Robot and Human Interactive Communication (pp. 101-106). IEEE. https://doi.org/10.1109/roman.2007.4415061

[28] Ricks, D. J., \& Colton, M. B. (2010, May). Trends and considerations in robot-assisted autism therapy. In 2010 IEEE international conference on robotics and automation (pp. 43544359). IEEE. https://doi.org/10.1109/robot.2010.5509327 
[29] Pennisi, P., Tonacci, A., Tartarisco, G., Billeci, L., Ruta, L., Gangemi, S., \& Pioggia, G. (2016). Autism and social robotics: A systematic review. Autism Research, 9(2), 165-183. https://doi.org/10.1002/aur.1527

[30] Tschöpe, N., Reiser, J. E., \& Oehl, M. (2017, March). Exploring the uncanny valley effect in social robotics. In Proceedings of the Companion of the 2017 ACM/IEEE International Conference on Human-Robot Interaction (pp. 307-308). https://doi.org/10.1145/3029798. 3038319

[31] MacDorman, K. F. (2006, July). Subjective ratings of robot video clips for human likeness, familiarity, and eeriness: An exploration of the uncanny valley. In ICCS/CogSci-2006 long symposium: Toward social mechanisms of android science (pp. 26-29).

[32] Tung, F. W. (2016). Child perception of humanoid robot appearance and behavior. International Journal of Human-Computer Interaction, 32(6), 493-502. https://doi.org/ 10.1080/10447318.2016.1172808

[33] Campolo, D., Taffoni, F., Schiavone, G., Laschi, C., Keller, F., \& Guglielmelli, E. (2008, August). A novel technological approach towards the early diagnosis of neurodevelopmental disorders. In 2008 30th Annual International Conference of the IEEE Engineering in Medicine and Biology Society (pp. 4875-4878). IEEE. https://doi.org/10.1109/iembs.2008. $\underline{4650306}$

[34] Boucenna, S., Narzisi, A., Tilmont, E., Muratori, F., Pioggia, G., Cohen, D., \& Chetouani, M. (2014). Interactive Technologies for Autistic Children: A review. Cognitive Computation, 6(4), 722-740. https://doi.org/10.1007/s12559-014-9276-x

[35] Belpaeme, T., Kennedy, J., Ramachandran, A., Scassellati, B., \& Tanaka, F. (2018). Social robots for education: A review. Science robotics by American Association for the Advancement of Science, 3(21), eaat5954. https://doi.org/10.1126/scirobotics.aat5954

[36] Koegel, R. L., Koegel, L. K., \& McNerney, E. K. (2001). Pivotal areas in intervention for autism. Journal of Clinical Child \& Adolescent Psychology, 30(1), 19-32. https://doi.org/ 10.1207/s15374424jccp3001_4

[37] Kozima, H., Nakagawa, C., \& Yasuda, Y. (2007). Children-robot interaction: a pilot study in autism therapy. Progress in brain research, 164, 385-400. https://doi.org/10.1016/s00796123(07)64021-7

[38] Thaut, M. H., \& Hodges, D. A. (Eds.). (2019). The Oxford Handbook of Music and the Brain. Oxford University Press.

[39] Chella, A., Dindo, H., Sorbello, R., Nishio, S., \& Ishiguro, H. (2012). Sing with the Telenoid. In teleoperated android as a tool for cognitive studies, communication and art. Sapporo, Giappone

[40] Taheri, A., Meghdari, A., Alemi, M., \& Pouretemad, H. (2019). Teaching music to children with autism: a social robotics challenge. Scientia Iranica, 26(Special Issue on: SocioCognitive Engineering), 40-58. https://doi.org/10.24200/sci.2017.4608

[41] Hanna, J. L. (1987). To dance is human: A theory of nonverbal communication. University of Chicago Press.

[42] Sawada, M., Suda, K., \& Ishii, M. (2003). Expression of emotions in dance: Relation between arm movement characteristics and emotion. Perceptual and motor skills, 97(3), 697708. https://doi.org/10.2466/pms.2003.97.3.697

[43] Yetti, E., Syarah, E. S., Pramitasari, M., Syarfina, S., \& Susanti, D. (2019, February). The influence of the dance creativity on executive functions of early childhood. In International Conference on Arts and Design Education (ICADE 2018). Atlantis Press. https://doi.org/ 10.2991/icade-18.2019.59

[44] Conti, D., Di Nuovo, S., Buono, S., Trubia, G., \& Di Nuovo, A. (2015, August). Use of robotics to stimulate imitation in children with Autism Spectrum Disorder: A pilot study in 
a clinical setting. In 2015 24th IEEE International Symposium on Robot and Human Interactive Communication (RO-MAN) (pp. 1-6). IEEE. https://doi.org/10.1109/roman.2015.73 $\underline{33589}$

[45] So, W. C., Cheng, C. H., Lam, W. Y., Wong, T., Law, W. W., Huang, Y., ... \& Wong, W. (2019). Robot-based play-drama intervention may improve the narrative abilities of Chinese-speaking preschoolers with autism spectrum disorder. Research in developmental disabilities, 95, 103515. https://doi.org/10.1016/j.ridd.2019.103515

[46] Bates, E., Dale, P. S., \& Thal, D. (1995). Individual differences and their implications for theories of language development. The handbook of child language, 30, 96-151. https:// doi.org/10.1111/b.9780631203124.1996.00005.x

[47] Duinmeijer, I., de Jong, J., \& Scheper, A. (2012). Narrative abilities, memory and attention in children with a specific language impairment. International Journal of Language \& Communication Disorders, 47(5), 542-555. https://doi.org/10.1111/j.1460-6984.2012.0016 $\underline{4 . \mathrm{X}}$

[48] Cooney, M. D., \& Menezes, M. L. R. (2018). Design for an art therapy robot: An explorative review of the theoretical foundations for engaging in emotional and creative painting with a robot. Multimodal Technologies and Interaction, 2(3), 52. https://doi.org/10.3390/m $\underline{\text { ti2030052 }}$

[49] Muri, S. A. (2007). Beyond the face: Art therapy and self-portraiture. The Arts in Psychotherapy, 34(4), 331-339. https://doi.org/10.1016/j.aip.2007.05.002

[50] Killeen, J. P., Evans, G. W., \& Danko, S. (2003). The role of permanent student artwork in students' sense of ownership in an elementary school. Environment and Behavior, 35(2), 250-263. https://doi.org/10.1177/0013916502250133

[51] Stuckey, H. L., \& Nobel, J. (2010). The connection between art, healing, and public health: A review of current literature. American journal of public health, 100(2), 254-263. https:// doi.org/10.2105/ajph.2008.156497

[52] Zhang, Y., Song, W., Tan, Z., Zhu, H., Wang, Y., Lam, C. M., \& Chen, J. (2019). Could social robots facilitate children with autism spectrum disorders in learning distrust and deception?. Computers in Human Behavior, 98, 140-149. https://doi.org/10.1016/j.chb.2019. $\underline{04.008}$

[53] Ding, X. P., Heyman, G. D., Fu, G., Zhu, B., \& Lee, K. (2018). Young children discover how to deceive in 10 days: A microgenetic study. Developmental science, 21(3), e12566. https://doi.org/10.1111/desc. 12566

[54] Storey, K. (2000). Teaching beginning chess skills to students with disabilities. Preventing School Failure: Alternative Education for Children and Youth, 44(2), 45-49. https://doi. org/10.1080/10459880009599782

[55] Carrera, L., Morales, F., Tobar, J., \& Loza, D. (2017). MARTI: A Robotic Chess Module with Interactive Table, for Learning Purposes. In Proceedings of the World Congress on Engineering and Computer Science (Vol. 2).

[56] Matuszek, C., Mayton, B., Aimi, R., Deisenroth, M. P., Bo, L., Chu, R., \& Fox, D. (2011, May). Gambit: An autonomous chess-playing robotic system. In 2011 IEEE International Conference on Robotics and Automation (pp. 4291-4297). IEEE. https://doi.org/10.1109/ic $\underline{\text { ra. } 2011.5980528}$

[57] Tong, G., Qu, Y., \& Cheng, T. (2009, October). Human-computer interactive gaming system-a chinese chess robot. In 2009 IEEE/RSJ International Conference on Intelligent Robots and Systems (pp. 984-987). IEEE. https://doi.org/10.1109/iros.2009.5354813

[58] Hocine, N., \& Gouaich, A. (2013). Difficulty and scenario adaptation: an approach to customize therapeutic games. In Serious games for healthcare: Applications and implications (pp. 107-134). IGI Global. https://doi.org/10.4018/978-1-4666-1903-6.ch006 
[59] Jerčić, P., Hagelbäck, J., \& Lindley, C. (2019). An affective serious game for collaboration between humans and robots. Entertainment Computing, 32, 100319. https://doi.org/10.101 6/j.entcom.2019.100319

[60] Tsiakas, K., Papakostas, M., Chebaa, B., Ebert, D., Karkaletsis, V., \& Makedon, F. (2016, June). An interactive learning and adaptation framework for adaptive robot assisted therapy. In Proceedings of the 9th ACM International Conference on PErvasive Technologies Related to Assistive Environments (pp. 1-4). https://doi.org/10.1145/2910674.2935857

[61] Galantino, M. L., Galbavy, R., \& Quinn, L. (2008). Therapeutic effects of yoga for children: a systematic review of the literature. Pediatric Physical Therapy, 20(1), 66-80. https ://doi.org/10.1097/pep.0b013e31815f1208

[62] Mohanty, S., Pradhan, B., \& Nagathna, R. (2014). The effect of yoga practice on proprioception in congenitally blind students. British Journal of Visual Impairment, 32(2), 124135. https://doi.org/10.1177/0264619614522132

[63] Jensen, P. S., \& Kenny, D. T. (2004). The effects of yoga on the attention and behavior of boys with attention-deficit/hyperactivity disorder (ADHD). Journal of attention disorders, 7(4), 205-216. https://doi.org/10.1177/108705470400700403

[64] Kaur, M., \& Bhat, A. (2019). Creative Yoga Intervention Improves Motor and Imitation Skills of Children with Autism Spectrum Disorder. Physical therapy, 99(11), 1520-1534. https://doi.org/10.1093/ptj/pzz115

[65] Goertzel, B., Mossbridge, J., Monroe, E., Hanson, D., \& Yu, G. (2017). Humanoid robots as agents of human consciousness expansion. arXiv preprint arXiv:1709.07791.

[66] Dorjee, D. (2016). Defining contemplative science: The metacognitive self-regulatory capacity of the mind, context of meditation practice and modes of existential awareness. Frontiers in psychology, 7, 1788. https://doi.org/10.31231/osf.io/9f65j

[67] Wama, T., Higuchi, M., Sakamoto, H., \& Nakatsu, R. (2004). Realization of tai-chi motion using a humanoid robot. In Building the Information Society (pp. 59-64). Springer, Boston, MA. https://doi.org/10.1007/978-1-4020-8157-6_9

[68] Chen, W., Gao, N., Wang, H., \& Sun, D. (2011, December). Implementation of Tai Chi Chuan on humanoid robot. In Proceedings of 2011 International Conference on Computer Science and Network Technology (Vol. 2, pp. 1128-1131). IEEE. https://doi.org/10.1109/ iccsnt.2011.6182159

[69] Sarabzadeh, M., Azari, B. B., \& Helalizadeh, M. (2019). The effect of six weeks of Tai Chi Chuan training on the motor skills of children with Autism Spectrum Disorder. Journal of bodywork and movement therapies, 23(2), 284-290. https://doi.org/10.1016/j.jbmt.2019. $\underline{01.007}$

[70] Wang, K. J., Sun, M., Zhang, L., \& Mao, Z. H. (2015, August). Mastering human-robot interaction control techniques using Chinese Tai Chi Chuan: Mutual learning, intention detection, impedance adaptation, and force borrowing. In 2015 Joint IEEE International Conference on Development and Learning and Epigenetic Robotics (ICDL-EpiRob) (pp. 104105). IEEE. https://doi.org/10.1109/devlrn.2015.7346123

[71] Costescu, C. A., Vanderborght, B., \& David, D. O. (2017). Robot-enhanced CBT for dysfunctional emotions in social situations for children with ASD.. Journal of Evidence-Based Psychotherapies, 17(2).

[72] Romero, M., Lepage, A., \& Lille, B. (2017). Computational thinking development through creative programming in higher education. International Journal of Educational Technology in Higher Education, 14(1), 42. https://doi.org/10.1186/s41239-017-0080-Z

[73] Knight, V. F., Wright, J., \& DeFreese, A. (2019). Teaching robotics coding to a student with ASD and severe problem behavior. Journal of autism and developmental disorders, 49(6), 2632-2636. https://doi.org/10.1007/s10803-019-03888-3 
[74] Albo-Canals, J., Martelo, A. B., Relkin, E., Hannon, D., Heerink, M., Heinemann, M., \& Bers, M. U. (2018). A pilot study of the KIBO robot in children with severe ASD. International Journal of Social Robotics, 10(3), 371-383. https://doi.org/10.1007/s12369-018-047 $\underline{9-2}$

[75] Edison. https://meetedison.com/Accessed 23 Jan 2020

[76] Lego. https://www.lego.com/Accessed 23 Jan 2020

\section{$7 \quad$ Authors}

Eleni Mitsea is with Institute of Informatics and Telecommunications - Net Media Lab \& Mind-Brain R\&D, Agia Paraskevi, 153 10, Athens, Greece (e-mail: e.mitsea@gmail.com).

Niki Lytra is with Institute of Informatics and Telecommunications - Net Media Lab \& Mind-Brain R\&D, Agia Paraskevi, 153 10, Athens, Greece (e-mail: niki1yt@gmail.com).

Antigoni Akrivopoulou is with Institute of Informatics and Telecommunications Net Media Lab \& Mind-Brain R\&D, Agia Paraskevi, 153 10, Athens, Greece (e-mail: antigoniakr@hotmail.com).

Athanasios Drigas is a Research Director at N.C.S.R. 'Demokritos', Institute of Informatics and Telecommunications - Net Media Lab \& Mind-Brain R\&D, Agia Paraskevi, 153 10, Athens, Greece (e-mail dr@ iit.demokritos.gr).

Article submitted 2020-03-13. Resubmitted 2020-04-08. Final acceptance 2020-04-09. Final version published as submitted by the authors. 